\title{
Evaluation of the Symptomatic Treatment of Residual Neurological Symptoms in Wilson Disease
}

\author{
Sara Hölscher ${ }^{a}$ Barbara Leinweber ${ }^{a}$ Harald Hefter $^{b} \quad$ Ulrike Reuner $^{c}$ \\ Peter Günther $^{d} \quad$ Karl Heinz Weiss ${ }^{e}$ Wolfgang H. Oertel ${ }^{a} \quad$ Jens Carsten Möller ${ }^{a}$ \\ ${ }^{a}$ Department of Neurology, Philipps University, Marburg, ${ }^{b}$ Department of Neurology, Heinrich-Heine University, \\ Düsseldorf, ' Department of Neurology, Technical University, Dresden, ${ }^{\mathrm{d}}$ Department of Neurology, University Leipzig, \\ Leipzig, and ${ }^{\mathrm{D}}$ Department of Gastroenterology, Ruprecht-Karls University, Heidelberg, Germany
}

\section{Key Words}

Wilson disease $\cdot$ Symptomatic treatment $\cdot$ Movement disorder

\begin{abstract}
The intention of this analysis was to identify patients with treated Wilson disease (WD) and residual neurological symptoms in order to determine whether or not they were undergoing any treatment in addition to the common decoppering medication. Moreover, the effects of any symptomatic medication were analyzed. Two samples of WD patients were investigated either by a mailed questionnaire survey $(n=135)$ or by a retrospective analysis $(n=75)$. A considerable proportion of patients still suffered from neurological symptoms ( $n=106,50.5 \%$ ), of whom a relatively small proportion was treated symptomatically ( $n=33,31.1 \%$ ). The documented effects varied substantially, with anticholinergics and botulinum toxin (against dystonia) and primidone (against tremor) apparently being the most promising compounds. Further studies are required to analyze the symptomatic treatment of WD patients with residual neurological symptoms in more detail.

Copyright $\odot 2010$ S. Karger AG, Base
\end{abstract}

\section{Introduction}

Wilson disease (WD) is an autosomal-recessive disorder of copper metabolism leading to excessive accumulation of copper in several body organs and tissues affecting mainly the liver and/or the brain [1-3]. The disease occurs in about 1 of every 40,000 persons [4]. The spectrum of possible clinical manifestations varies considerably. On the one hand, WD may present with hepatitis, chronic cirrhosis, liver failure or just elevated serum transaminases [2]. On the other hand, neurological symptoms, especially movement disorders caused by dysfunction of the basal ganglia and the cerebellum, are described [5]. A psychiatric presentation including depression and changes in behavior is also possible. Due to the rarity and unspecific beginning of the disease, diagnosis is often delayed [4]. With early diagnosis and medical therapy, progress can be avoided in most cases, whereas without treatment the disease is usually lethal [6]. However, despite the removal of excess copper by chelating agents, WD patients can still feature residual neurological symptoms [7]. To our knowledge, there are no data on the symptomatic treatment of WD patients with such symptoms and its potential effects.

\section{KARGER}

Fax +41613061234 E-Mail karger@karger.ch www.karger.com
Jens Carsten Möller, MD

Department of Neurology, Philipps University

Rudolf-Bultmann-Strasse 8, DE-35039 Marburg (Germany)

Tel. +49 6421586 5372, Fax +49 64215867055

E-Mail carsten.moeller@med.uni-marburg.de 


\section{Patients and Methods}

The study was approved by the Institutional Review Board of Philipps University and consisted of 2 parts.

First, a questionnaire, a patient information leaflet and an informed consent were mailed to the members of 'Morbus Wilson e.V., the German self-support group. Patients who were interested to participate in this survey had to return the questionnaire along with the signed informed consent. A telephone number was provided in case of further inquiries. The questionnaire assessed the usual demographic data, the age of onset, presentation at disease onset and the current decoppering treatment. Symptoms at disease onset could be classified by the patient as neurological, hepatic, psychiatric and other/none/unknown. Then, the current residual neurological symptoms were addressed. If any were reported, the participants were requested to specify whether the symptoms could be assigned to 1 or several of the following subgroups: dystonia, parkinsonism and/or postural and action tremor. For this purpose, respective explanations and some space for a free text were provided. Subsequently, it was asked if the patient was currently or had previously been treated symptomatically. If so, the type and duration of treatment were to be recorded. Finally, the subjective efficacy of the treatment was rated on a scale from 0 to 4 (0 - no change, 1 - slight, 2 - moderate, 3 - good, 4 - very good improvement). Uncertainties in the questionnaire survey were clarified by telephone, if the patient had agreed to be contacted. The questionnaire is provided in an English translation in the online supplementary material (see, www. karger.com/doi/10.1159/000316066).

Second, the files of WD patients from 5 specialized mainly neurological outpatient clinics in Germany were retrospectively analyzed using an identical data set.

The obtained data were evaluated by descriptive statistics, using SPSS, version 15.0 for Windows.

\section{Results}

A total of $210 \mathrm{WD}$ patients were analyzed. One hundred and thirty-seven of 270 contacted patients participated in the mailed questionnaire survey; 135 of these questionnaires could be evaluated. Additionally, the files of 87 patients were available, of whom 12 also participated in the mailed questionnaire survey. Accordingly, the remaining 75 patient files were used for the retrospective analysis. Sixty-one patients $(45.2 \%)$ who participated in the mailed questionnaire survey subjectively reported the presence of neurological symptoms, whereas neurological symptoms were identified in 45 patients (60\%) of the retrospective analysis (i.e. $50.5 \%$ of the whole study population). The demographic and clinical characteristics of both samples are presented in table 1. Both samples showed a similar sex distribution, mean age, age of onset and disease duration, distribution of symptoms at disease onset and decoppering therapy. Although our study was not designed to address this issue, we would like to mention that fewer patients had residual neurological symptoms under a D-penicillamine than under a trientine monotherapy $(\mathrm{p}=0.008)$.

Sixteen of 61 patients (26.2\%) of the mailed questionnaire survey and 17 of 45 patients (37.7\%) of the retrospective analysis (had) received symptomatic treatment (i.e. $31.1 \%$ of the whole study population). The assessment of subjective efficacy was not available in 3 patients of the mailed questionnaire survey (unknown medication, $\mathrm{n}=$ 2 ; metixene and tiapride, $n=1$ ), whereas no documentation of the effect was identified in 5 patients of the retrospective analysis (trihexyphenidyl, $\mathrm{n}=3$; biperiden, $\mathrm{n}=$ 1 ; baclofen, $n=1$ ). Table 2 provides a summary of the used medications and their proposed effects in altogether 25 patients. With respect to the mailed questionnaire survey, the classification of symptoms and their improvement by therapy were primarily based on the self-assessment of the patients. In cases where a medication was used in the presence of the usual target symptom, it was assumed that the reported efficacy was probably due to the administered compound. Apart from that, we did not consider it feasible to assign the effect of a given drug to a certain symptom merely based on a mailed questionnaire survey (and telephone interviews) or a retrospective analysis. Therefore, it was mentioned in table 2 ('comments') when a medication was administered in the absence of the usual target symptom. Furthermore, we interpreted the assumed efficacy of a single compound in patients taking several drugs with increased caution (see table 2 and Discussion).

\section{Discussion}

In a previous report we already suggested that a substantial proportion of WD patients still features residual neurological symptoms [7]. Furthermore, almost half of the patients taking part in the mailed questionnaire survey subjectively reported residual neurological symptoms. This estimate was corroborated by the results of the retrospective analysis where residual neurological symptoms were identified in $60 \%$ of the patients. This moderately higher prevalence was probably due to a selection bias, since the retrospective analysis was performed among patients of specialized mainly neurological outpatient clinics. However, the results from both investigated samples emphasize that residual neurological symptoms represent a frequent feature in WD patients despite a long-term decoppering therapy. Although not addressed 
Table 1. Demographic and clinical data

\begin{tabular}{|c|c|c|c|c|c|c|c|c|c|c|c|c|}
\hline & \multicolumn{6}{|c|}{ Questionnaire survey patients $(\mathrm{n}=135)$} & \multicolumn{6}{|c|}{ Retrospectively analyzed patients $(\mathrm{n}=75)$} \\
\hline & $\mathrm{n}$ & $\%$ & mean & SD & $\min$. & $\max$. & $\mathrm{n}$ & $\%$ & mean & SD & $\min$. & $\max$. \\
\hline \multicolumn{13}{|l|}{ Sex } \\
\hline Female & 86 & 63.7 & & & & & 45 & 60.0 & & & & \\
\hline Male & 49 & 36.3 & & & & & 30 & 40.0 & & & & \\
\hline Mean age, years & & & $40.9(\mathrm{n}=134)$ & 11.1 & 19 & 67 & & & 42.3 & 12.2 & 18 & 73 \\
\hline Mean age at onset, years & & & $21.3(\mathrm{n}=127)$ & 9.3 & 4 & 46 & & & $19.7(\mathrm{n}=61)$ & 8.5 & 5 & 71 \\
\hline Duration of disease, years & & & $19.8(\mathrm{n}=127)$ & 10.9 & 1 & 42 & & & $23.8(n=61)$ & 12.8 & 2 & 53 \\
\hline \multicolumn{13}{|l|}{ Symptoms at disease onset } \\
\hline Neurological & 42 & 31.1 & & & & & 25 & 33.3 & & & & \\
\hline Psychiatric & 0 & 0.0 & & & & & 1 & 1.3 & & & & \\
\hline Hepatic & 39 & 28.9 & & & & & 18 & 24.0 & & & & \\
\hline Others/none/not known & 22 & 16.3 & & & & & 15 & 20.0 & & & & \\
\hline Neurological + psychiatric & 4 & 3.0 & & & & & 5 & 6.7 & & & & \\
\hline Neurological + hepatic & 16 & 11.9 & & & & & 6 & 8.0 & & & & \\
\hline Psychiatric + hepatic & 3 & 2.2 & & & & & 0 & 0.0 & & & & \\
\hline Other combinations & 9 & 6.6 & & & & & 5 & 6.7 & & & & \\
\hline \multicolumn{13}{|l|}{ Administration of } \\
\hline D-Penicillamine & 57 & 42.2 & & & & & 35 & 46.6 & & & & \\
\hline Trientine & 33 & 24.4 & & & & & 6 & 8.0 & & & & \\
\hline Zinc & 29 & 21.5 & & & & & 17 & 22.6 & & & & \\
\hline D-Penicillamine + zinc & 9 & 6.6 & & & & & 9 & 12.0 & & & & \\
\hline Trientine + zinc & 7 & 5.2 & & & & & 5 & 6.6 & & & & \\
\hline Not known & 0 & 0.0 & & & & & 3 & 4.0 & & & & \\
\hline
\end{tabular}

in the present study, this observation is compatible with a recent publication reporting a prevalence of psychiatric symptoms in up to $70 \%$ of treated WD patients [8].

According to our knowledge, this study represents the first approach of how WD patients with residual neurological symptoms are symptomatically treated. The used medications covered a broad range of different drug classes reflecting the complex phenotype of patients with WD. Accordingly, anticholinergics and botulinum toxin as routine medications for dystonia, $\beta$-blockers and primidone as frequently used medications for tremor, and dopaminergic compounds as typical antiparkinsonian drugs were most frequently administered in our patients.

Anticholinergics such as trihexyphenidyl (as monotherapy, $\mathrm{n}=3$ ) had a moderate to good effect in 2 patients and may hypothetically not only exert a beneficial effect on dystonia, but also on parkinsonism in patients with WD. Botulinum toxin (as monotherapy, $\mathrm{n}=3$ ) had a slight to good effect in these patients, which could be expected due to its peripheral mode of action in the treat- ment of dystonia. Baclofen (as monotherapy, $\mathrm{n}=1$ ) had a good effect in this patient and may represent a possible treatment option in the treatment of dystonia in WD patients.

$\beta$-Blockers such as propranolol (as monotherapy, $\mathrm{n}=$ 3) had a slight to good effect in these patients (however, in 2 patients with a combination therapy, no effect at all was reported). According to the results of this preliminary study, primidone (as monotherapy, $\mathrm{n}=5$ ) appears to be a more promising compound in the treatment of postural or action tremor in WD, since it had a moderate to very good effect in 4 patients reporting tremor.

L-Dopa (as monotherapy, $\mathrm{n}=1$ ) did not have any effect in this patient. Since parkinsonism in WD patients is probably due to a lesion of both presynaptic (nigral) and postsynaptic (striatal) neurons, it could be discussed whether a dopaminergic therapy should only be initiated in WD patients with a normal (or only slightly pathological) dopamine receptor SPECT [9]. Furthermore, apomorphine could be used to assess whether a given patient may respond to a dopaminergic therapy or not. 
Table 2. Effects of symptomatic treatment

\begin{tabular}{|c|c|c|c|c|}
\hline Drug class & Medication & Subjective efficacy & Symptoms & Comments \\
\hline \multicolumn{5}{|l|}{ Questionnaire } \\
\hline Anticholinergics & trihexyphenidyl $(\mathrm{n}=1)$ & moderate $(n=1)$ & parkinsonism, dystonia $(\mathrm{n}=1)$ & \\
\hline BTX & $\operatorname{idem}(\mathrm{n}=2)$ & $\operatorname{good}(\mathrm{n}=2)$ & $\begin{array}{l}\text { dystonia }(\mathrm{n}=1) \\
\text { parkinsonism, dystonia }(\mathrm{n}=1)\end{array}$ & \\
\hline \multirow[t]{3}{*}{$\beta$-Blockers } & propranolol $(n=3)$ & $\operatorname{good}(\mathrm{n}=1)$ & tremor $(\mathrm{n}=1)$ & \\
\hline & & moderate $(n=1)$ & tremor, parkinsonism, dystonia $(\mathrm{n}=1)$ & \\
\hline & & slight $(\mathrm{n}=1)$ & tremor $(\mathrm{n}=1)$ & \\
\hline Barbiturates & primidone $(\mathrm{n}=1)$ & moderate $(\mathrm{n}=1)$ & parkinsonism, dystonia $(\mathrm{n}=1)$ & no report of tremor \\
\hline Dopaminergic compounds & L-dopa $(\mathrm{n}=1)$ & none $(\mathrm{n}=1)$ & parkinsonism $(\mathrm{n}=1)$ & \\
\hline \multirow[t]{2}{*}{ Dopamine antagonists } & tiapride $(\mathrm{n}=2)$ & $\operatorname{good}(\mathrm{n}=1)$ & tremor, parkinsonism, dystonia $(\mathrm{n}=1)$ & $\begin{array}{l}\text { hyperkinesia not } \\
\text { specifically addressed }\end{array}$ \\
\hline & & none $(\mathrm{n}=1)$ & tremor, dystonia $(\mathrm{n}=1)$ & \\
\hline Others & n.a. & n.a. & n.a. & \\
\hline \multirow[t]{3}{*}{ Several } & biperiden, BTX (n = 1) & moderate $(\mathrm{n}=1)$ & parkinsonism, dystonia $(\mathrm{n}=1)$ & \\
\hline & $\begin{array}{l}\text { trihexyphenidyl, BTX, } \\
\text { baclofen }(\mathrm{n}=1)\end{array}$ & moderate $(\mathrm{n}=1)$ & parkinsonism, dystonia $(\mathrm{n}=1)$ & \\
\hline & $\begin{array}{l}\beta \text {-blocker (unknown), } \\
\text { primidone, L-dopa, } \\
\text { clonazepam }(\mathrm{n}=1)\end{array}$ & none $(\mathrm{n}=1)$ & tremor, dystonia $(\mathrm{n}=1)$ & no report of parkinsonism \\
\hline \multicolumn{5}{|l|}{ Retrospective analysis } \\
\hline \multirow[t]{2}{*}{ Anticholinergics } & trihexyphenidyl $(\mathrm{n}=2)$ & $\operatorname{good}(\mathrm{n}=1)$ & parkinsonism, dystonia $(\mathrm{n}=1)$ & \\
\hline & & none $(\mathrm{n}=1)$ & parkinsonism, dystonia $(\mathrm{n}=1)$ & \\
\hline BTX & idem $(n=1)$ & slight $(\mathrm{n}=1)$ & tremor, dystonia $(\mathrm{n}=1)$ & \\
\hline$\beta$-Blockers & n.a. & n.a. & n.a. & \\
\hline \multirow[t]{3}{*}{ Barbiturates } & primidone $(\mathrm{n}=4)$ & very good $(n=2)$ & tremor, dystonia $(\mathrm{n}=1)$, dystonia $(\mathrm{n}=1)^{\circ}$ & ${ }^{\circ}$ probably initial tremor \\
\hline & & $\operatorname{good}(\mathrm{n}=1)$ & tremor, dystonia $(\mathrm{n}=1)$ & \\
\hline & & moderate $(n=1)$ & tremor, parkinsonism, dystonia $(\mathrm{n}=1)$ & \\
\hline Dopaminergic compounds & n.a. & n.a. & n.a. & \\
\hline Dopamine antagonists & tiapride $(\mathrm{n}=1)$ & slight $(\mathrm{n}=1)$ & dystonia $(\mathrm{n}=1)$ & also hyperkinesia \\
\hline Others & baclofen $(\mathrm{n}=1)$ & $\operatorname{good}(\mathrm{n}=1)$ & tremor, parkinsonism, dystonia $(\mathrm{n}=1)$ & \\
\hline \multirow[t]{3}{*}{ Several } & $\begin{array}{l}\text { trihexyphenidyl, BTX, } \\
\text { L-dopa }(\mathrm{n}=1)\end{array}$ & $\operatorname{good}(n=1)$ & parkinsonism, dystonia $(\mathrm{n}=1)$ & \\
\hline & $\begin{array}{l}\text { BTX, tetrabenazine, } \\
\text { ropinirole }(\mathrm{n}=1)\end{array}$ & $\operatorname{good}(\mathrm{n}=1)^{\circ}$ & parkinsonism, dystonia $(\mathrm{n}=1)$ & $\begin{array}{l}{ }^{\circ} \text { due to effect of } \\
\text { tetrabenazine on } \\
\text { concomitant hyperkinesia }\end{array}$ \\
\hline & $\begin{array}{l}\text { propranolol, } \mathrm{L} \text {-dopa, } \\
\text { amantadine }(\mathrm{n}=1)\end{array}$ & none $(\mathrm{n}=1)$ & tremor, dystonia $(\mathrm{n}=1)$ & no report of parkinsonism \\
\hline
\end{tabular}

BTX = Botulinum toxin; tremor $=$ postural and action tremor; n.a. $=$ not assessed.

The results with respect to tiapride (as monotherapy, $\mathrm{n}=3$ ) are inconclusive since hyperkinesia is not a typical symptom in treated WD and was therefore not specifically addressed in the current study [7]. However, it is worth mentioning that tetrabenazine (in combination therapy) had a good effect on hyperkinesia in 1 patient. Likewise, the treatment of hypersalivation in WD patients by botulinum toxin was not covered by the present investigation.
Despite the large number of patients, this study has some methodological limitations since the results are derived either from a survey using an unvalidated questionnaire or a retrospective analysis. Also, several patients received a combination therapy impeding the interpretation of the obtained data with respect to the effect of a single compound. Therefore, these patients are shown in table 2 , but were usually not included in the 
discussion. These limitations were mainly owed to the rarity of the disease. Nevertheless, we think that this is an important investigation, since it underlines that residual neurological symptoms are a frequent phenomenon in treated WD and, for the first time, addresses their possible symptomatic treatment. Based on the available data, treatment with anticholinergics and botulinum toxin in WD patients with residual dystonia and with primidone in WD patients with persisting postural and action tremor, respectively, appears most promising.
Prospective studies on the symptomatic treatment of residual neurological symptoms in treated WD are highly recommended.

\section{Acknowledgments}

We thank all the patients who participated in the study and 'Morbus Wilson e.V.' for their organizational support. This study was supported by the German Ministry of Education and Research (BMB+F: GeNeMove 01GM0502).

\section{References}

1 Ferenci P: Pathophysiology and clinical features of Wilson disease. Met Brain Dis 2004; 19:229-239.

2 Roberts EA, Schilsky ML: A practice guideline on Wilson disease. Hepatology 2003;37: 1475-1492.

3 Ferenci P, Caca K, Loudianos G, Mieli-Vergani G, Tanner S, Sternlieb I, Schilsky M, Cox D, Berr F: Diagnosis and phenotypic classification of Wilson disease. Liver Int 2003;23:139-142.

4 Brewer GJ: Recognition, diagnosis, and management of Wilson's disease. Proc Soc Exp Biol Med 2000;223:39-46.
5 Brewer GJ: Neurologically presenting Wilson's disease: epidemiology, pathophysiology and treatment. CNS Drugs 2005;19:185192.

6 Czlonkowska A, Tarnacka B, Litwin T, Gajda J, Rodo M: Wilson's disease - cause of mortality in 164 patients during 1992-2003 observation period. J Neurol 2005;252:698703.

7 Leinweber B, Möller JC, Scherag A, Reuner U, Günther P, Lang CJG, Schmidt HHJ, Schrader C, Bandmann O, Czlonkowska A, Oertel WH, Hefter H: Evaluation of the Unified Wilson's Disease Rating Scale (UWDRS) in German patients with treated Wilson's disease. Mov Disord 2008;23:5462 .
8 Svetel M, Potrebic A, Pekmezovic T, Tomic A, Kresojevic N, Jesic R, Dragasevic N, Kostic VS: Neuropsychiatric aspects of treated Wilson's disease. Parkinsonism Relat Disord 2009; 15:772-775.

9 Barthel M, Hermann W, Kluge R, Hesse S, Collingridge DR, Wagner A, Sabri O: Concordant pre- and postsynaptic deficits of dopaminergic neurotransmission in neurologic Wilson disease. AJNR Am J Neuroradiol 2003;24:234-238. 